\section{(C) \\ OPEN ACCESS}

\title{
Biliary strictures: endoscopic assessment and management
}

\author{
Bharat Paranandi, ${ }^{1}$ Kofi W Oppong ${ }^{2}$
}

\begin{abstract}
${ }^{1}$ Department of Gastroenterology, Leeds Teaching Hospitals NHS Trust, Leeds, UK

${ }^{2}$ HPB Unit, Freeman Hospital, Newcastle upon Tyne Hospitals NHS Trust, Newcastle upon Tyne, UK
\end{abstract}

\section{Correspondence to} Dr Kofi W Oppong, Department of Gastroenterology, Freeman Hospital, Freeman Rd, Newcastle upon Tyne NE7 7DN, UK; Kofi. Oppong@nuth.nhs.uk

Received 3 November 2016 Accepted 11 December 2016

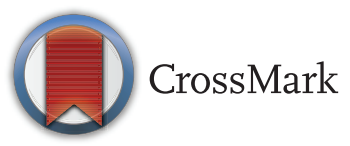

To cite: Paranandi B, Oppong KW. Frontline Gastroenterology

2017;8:133-137.

\begin{abstract}
The diagnosis of biliary strictures can be challenging. Endoscopy has an established role in the diagnosis and therapy of biliary strictures.

However, the diagnostic yield from conventional endoscopic retrograde cholangiopancreatography tissue sampling is modest. Improvements in existing technologies as well as the implementation of novel technologies and techniques have the potential to improve the diagnostic performance of endoscopy and expand its therapeutic role. Recent studies have enabled greater clarity about the role of preoperative biliary drainage and the choice of stents in this setting as well as the utility of metal stents in benign and malignant disease.
\end{abstract}

\section{BACKGROUND}

Biliary strictures (BS) are an everyday challenge in gastrointestinal clinical practice. The most pertinent and critical differentiation is between benign and malignant aetiology. This differentiation often poses a significant diagnostic and therapeutic challenge and extensive investigative workup may be required.

Most BS are of malignant aetiologyeither pancreatic adenocarcinoma, cholangiocarcinoma (CCA) or peri-ampullary cancer-and these tend to present at an advanced stage (rendering them unresectable). Less common malignant causes may include gallbladder cancer, hepatocellular carcinoma, lymphoproliferative and metastatic disease. Up to one-third of BS are benign. Benign causes include gallstones (Mirizzi's syndrome or inflammatory stricture) chronic pancreatitis, primary scelrosing cholangitis (PSC), IgG4-related sclerosing cholangitis (IgG4-SC), iatrogenic bile duct injury (following cholecystectomy), post-transplant strictures and other less common conditions. ${ }^{1}$

A recent study found $13.6 \%$ of patients undergoing surgical resection for a suspected Klatskin tumour had benign disease. $^{2}$ Such major surgery is associated with appreciable morbidity and not insignificant morbidity. Therefore, confirming the diagnosis before surgery is preferable.

In the rest of this article, we will discuss the role of endoscopy in the evaluation and management of BS.

\section{Endoscopic retrograde} cholangiopancreatography

Endoscopic retrograde cholangiopancreatography (ERCP) plays an important role in the management of BS and it is commonly performed to alleviate symptoms including jaundice and cholangitis.

Cholangiography can provide morphological characterisation and information for BS including location, extent, irregularity and shouldering but even in expert hands cholangiography alone is an unreliable means to differentiate between PSC, IgG4-SC and hilar CCA. ${ }^{3}$

Concurrent tissue sampling of BS can be achieved by biliary brush cytology or intraductal biliary biopsy. Biliary brushings is the most commonly performed tissue diagnostic technique performed for BS.

A 2015 meta-analysis of nine studies found that the sensitivity of brush cytology and intraductal biopsy in diagnosing malignant BS were $45 \%$ and $48 \%$, respectively. A combination of both only modestly increased the sensitivity to $59.4 \%$. Both techniques are almost 100\% specific. ${ }^{4}$

\section{Endoscopic ultrasonography-fine needle aspiration}

Endoscopic ultrasonography (EUS) provides the ability to identify a mass lesion not detected by other imaging modalities and enables high-definition imaging of stricture morphology (figure 1). EUS in 


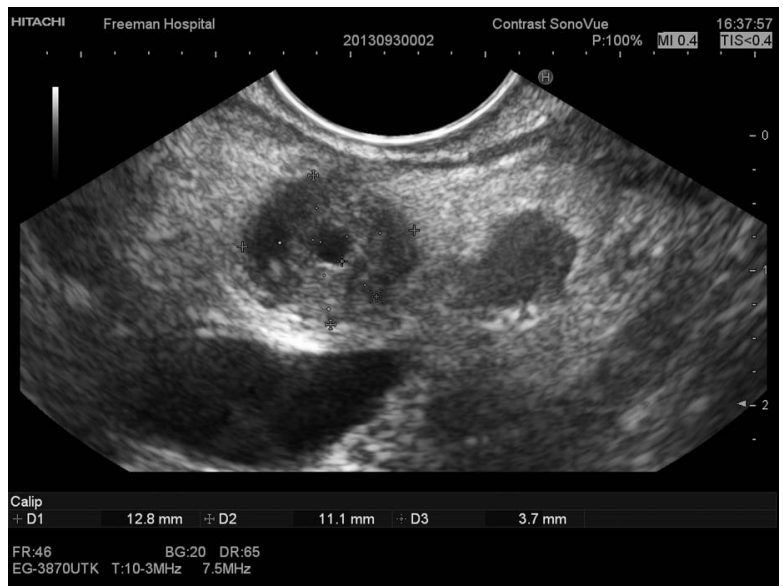

Figure 1 Linear endoscopic ultrasonography image showing a thickened and strictured proximal bile duct $13 \mathrm{~mm}$ in outer diameter.

addition facilitates staging by assessing regional lymphadenopathy and vascular involvement. Tissue acquisition using EUS-guided fine-needle aspiration (EUS-FNA) can also be performed (figure 2).

A recent meta-analysis of 20 studies demonstrated that pooled sensitivity and specificity of EUS-FNA for diagnosis of malignant BS were $80 \%$ and 97\%, respectively. ${ }^{5}$ Diagnostic sensitivity was higher in distal $(83 \%)$ than proximal $(76 \%)$ BS. The negative likelihood ratio was 0.26. Adverse events were rare (approximately 1\%) and generally mild in natureincluding self-controlled bleeding. This suggests that EUS-FNA is sensitive and highly specific for diagnosing malignancy in BS, but cannot be relied on to exclude malignancy. The possibility for tumour seeding of the needle track in potential surgical candidates is unresolved. A study from the Mayo Clinic found that during the tumour staging procedure, $83 \%$ of patients with a history of a positive FNA were found to have peritoneal metastasis along the needle tract. ${ }^{6}$ Conversely, a recent risk-adjusted single-centre study of 150 patients with CCA reported that

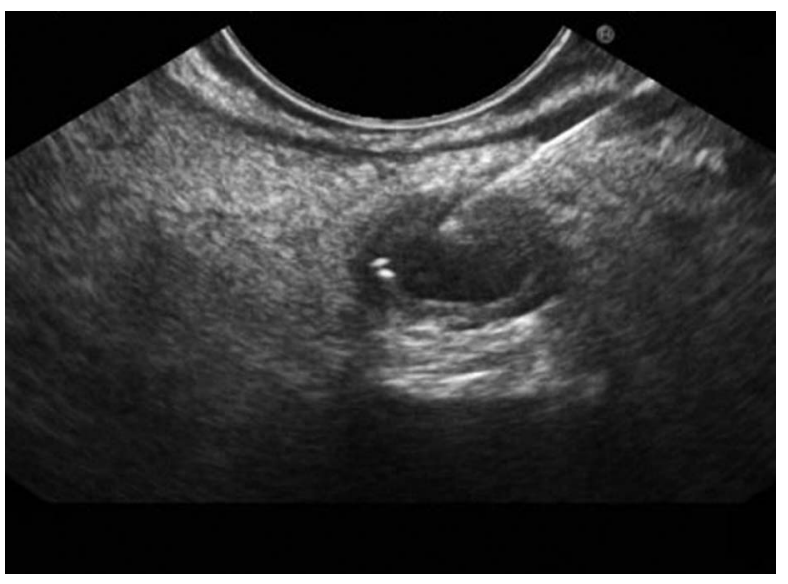

Figure 2 Endoscopic ultrasonography-fine needle aspiration of proximal biliary stricture, cytological analysis reported as suspicious of malignancy. preoperative EUS-FNA did not adversely affect either overall or progression-free survival ${ }^{7}$; however, the follow-up period in this study was relatively short. The risk of tumour seeding should be borne in mind when considering EUS-FNA in operable patients.

\section{Intraductal ultrasound}

During ERCP, a wire-guided mini-US probe can be advanced into the bile duct allowing three-dimensional and circumferential imaging of the extrahepatic bile duct and nearby vasculature.

A recent large series reported that $\mathrm{ERCP} /$ intraductal ultrasound (IDUS) (91\%) was superior to EUS (74\%) and CT $(73 \%)$ in providing an accurate diagnosis of bile duct strictures of uncertain aetiology. ${ }^{8}$ IDUS is unable to provide a tissue diagnosis or assess lymphadenopathy and is not currently widely used.

\section{Cholangioscopy}

Cholangioscopy involves direct visualisation of the bile ducts, but it has historically proved cumbersome owing to the need for multiple endoscopic operators, 'mother and baby' endoscopes as well as suboptimal visibility and picture clarity. The development in the last decade of a single operator cholangioscopy (SOC) system has renewed enthusiasm for this technique. The most widely used per-oral cholangioscope (Spyglass, Boston Scientific) can be inserted via the therapeutic channel of a duodenoscope and passed over a wire directly into the bile duct.

In a 2015 international multicentre, prospective study of 95 patients undergoing cholangioscopy and biopsy, the sensitivity for the diagnosis of malignancy was $51 \%$ for radiographic ERCP diagnosis, $78 \%$ for visual impression at direct cholangioscopy and 49\% for histology. ${ }^{9}$ In a UK multicentre cohort, the overall accuracy of cholangioscopy for diagnosing malignant lesions was $87 \% .^{10}$

\section{RECENT DEVELOPMENTS}

\section{Fluorescence in situ hybridisation}

Fluorescence in situ hybridisation (FISH) is an advanced cytological technique that uses the correlation between malignancy and chromosomal aneusomy. Chromosomes 3, 7, 9 and 17 are stained with fluorescently labelled probes and the cytological specimen assessed for polysomy. FISH has been shown to enhance tumour detection by approximately $10 \%-$ $30 \%$. A recent study of triple modality tests (cytology, biopsy and FISH) reported an overall sensitivity of $82 \%$, specificity of $100 \%$, positive predictive value (PPV) of $100 \%$ and negative predictive value (NPV) of $87 \% .^{11}$

\section{Digital cholangioscopy}

A second-generation digital system has recently become available. The digital Spyglass (Boston Scientific) provides a wider angle of view with significant 
improvement in image quality in a single-use device (figure 3). Preliminary data are encouraging. In a recent multicentre study, the sensitivity and specificity of SOC visual impression for diagnosis of malignancy were $90 \%$ and $95.8 \%$, respectively. The sensitivity and specificity of SOC-guided biopsies for diagnosis of malignancy were $85 \%$ and $100 \%$, respectively ${ }^{12}$; further prospective studies are required. The system is currently expensive, there are competitor devices in development from other companies. Competition will hopefully stimulate innovation and reduce costs.

\section{Confocal laser endomicroscopy}

Probe-based confocal laser endomicroscopy (pCLE; Cellvizio, Mauna Kea Technologies) is a novel technology that enables real-time high-resolution histological analysis of targeted tissue during endoscopy. pCLE uses a $1 \mathrm{~mm}$ wide fibre bundle for laser light propagation and collection of fluorescence. The imaging plane (pin hole) is fixed providing microscopic video sequences (9-12 frames/s). The field of view is 320 microns and imaging depth 40-70 microns. The probe is passed down either a catheter within the bile duct or a cholangioscope and placed in contact with the bile duct mucosa. Tissue is illuminated by a low powered laser focused into a single point. An intravenous injection of fluorescein is administered immediately prior to the procedure and stains cellular cytoplasm and extracellular matrix. The image obtained is akin to that of a low power microscope but in a horizontal rather than vertical plane (figure 4).

A multicentre study compared CLE with cholangioscopic targeted biopsy for the detection of malignancy in biliary tract strictures. The overall sensitivity of CLE was $76.4 \%$ with no difference in sensitivity, specificity or diagnostic accuracy when compared with biopsy. ${ }^{13}$

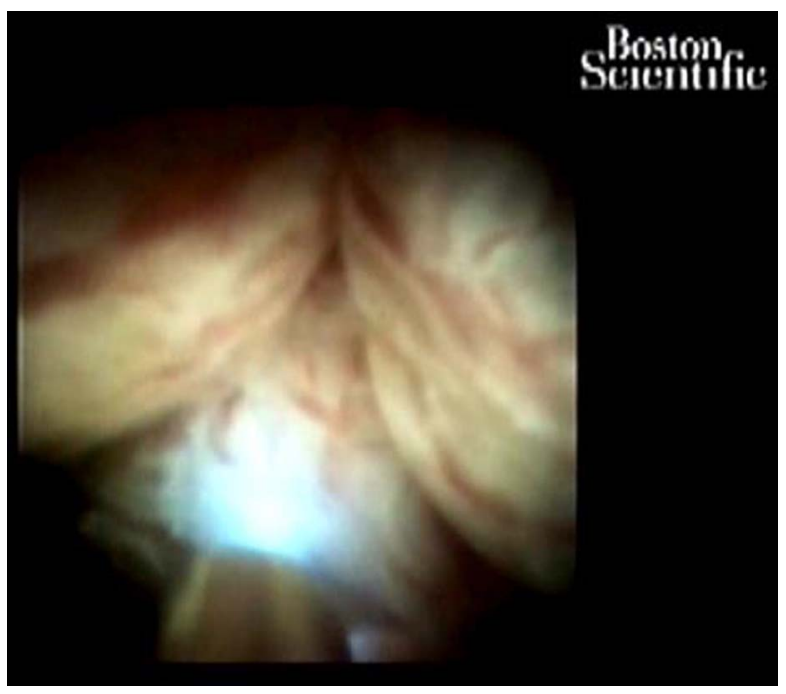

Figure 3 Digital Spyglass cholangioscopy and confocal laser endomicroscopy $(L E)$ in a patient with IgG4 cholangiopathy CLE probe is seen protruding into the frame inferiorly.

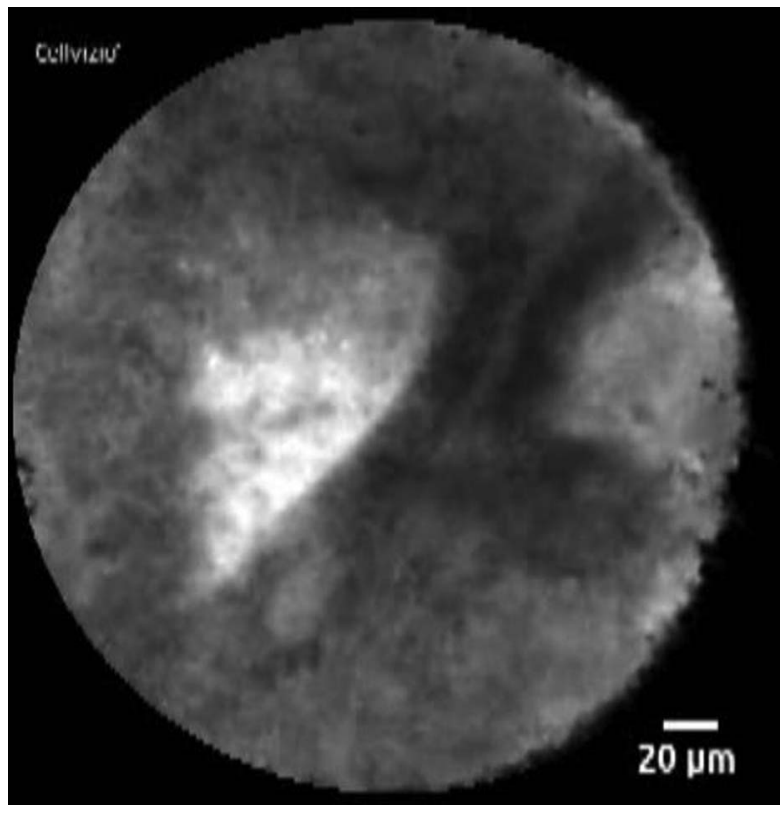

Figure 4 Confocal laser endomicroscopy image from patient with lgG4 cholangiopathy.

Another study compared CLE outcomes with those of definitive histology obtained by biopsy or surgery in cases of malignant lesions, and by surgery or 1-year follow-up in case of benign lesions. Sensitivity, specificity, PPV, NPV and accuracy with combination of pCLE with endobiliary and EUS biopsies were 100, $71,91,100$ and $93 \%$, respectively (with a significant increase of accuracy compared with endobiliary and EUS biopsies without pCLE, $\mathrm{p}=0.03) .{ }^{14}$

\section{Endoscopic management}

Stent placement at ERCP is a standard method of palliating biliary obstruction particularly for distal BS. The utility of preoperative endoscopic biliary drainage and role of metal stents in benign and malignant disease has become clearer recently. A multicentre, randomised controlled trial (RCT) reported higher morbidity and similar mortality among individuals with pancreatic head cancer undergoing placement of plastic biliary stent prior to surgical resection compared with those proceeding to surgery without preoperative drainage. ${ }^{15}$ This study excluded patients with bilirubin levels $>250 \mathrm{mmol} / \mathrm{L}$, those with evidence of biliary sepsis and patients due to have neoadjuvant chemoradiation. The same group recently reported an extension of their previous study that found significantly lower complication rate $(24 \%$ vs $46 \%)$ when fully covered self-expanding metal stents (FCSEMS) were used compared with plastic stents. ${ }^{16}$ They concluded that FCSEMS are preferable to plastic stents when preoperative drainage is required. The benefits of metal stents do not appear to be limited to the preoperative setting. A recent meta-analysis comparing plastic and metal stents in the setting of malignant biliary obstruction concluded 
that the latter are the treatment of choice for patients with distal as well as proximal disease. ${ }^{17}$

FCSEMS also have a role in benign disease; a large international, multicentre study reported successful resolution of benign distal BS in $75 \%$ of patients undergoing short-term placement of fully covered metal stents. ${ }^{18}$

In terms of endoscopic therapy, EUS-guided biliary drainage offers an alternative to percutaneous drainage in patients with biliary obstruction in whom standard ERCP is unsuccessful or not possible. A recent multicentre prospective series reported $89.5 \%$ clinical success rate and 10.5\% adverse events including one death, ${ }^{19}$ such preliminary data from expert centres are encouraging. However, an RCT versus percutaneous biliary drainage is required before this technique is advocated for routine use. Ablative therapy in the form of radiofrequency ablation (RFA) or photodynamic therapy can be delivered at the time of ERCP. RFA is a relatively new technique that has promise for maintaining stent patency and possibly improved survival $^{20}$; again prospective randomised controlled studies are urgently required.

\section{FUTURE POTENTIAL}

The establishment of EUS as a mature technology for assessment of BS, the arrival on stage of high-quality digital cholangioscopy and pCLE not to mention FISH and the possibly underused IDUS suggests a surfeit of riches in terms of endoscopic technologies and techniques to evaluate indeterminate BS in 2017. However, high-quality studies of multimodality endoscopic evaluation are urgently required to identify the most efficacious tests and appropriate sequence to achieve the holy grail of accurately, quickly and safely diagnosing indeterminate BS.

Contributors BP wrote the first draft. KWO wrote the second draft. Both authors contributed to the final manuscript.

Competing interests None declared.

Provenance and peer review Commissioned; externally peer reviewed.

Open Access This is an Open Access article distributed in accordance with the Creative Commons Attribution Non Commercial (CC BY-NC 4.0) license, which permits others to distribute, remix, adapt, build upon this work non-commercially, and license their derivative works on different terms, provided the original work is properly cited and the use is non-

commercial. See: http://creativecommons.org/licenses/by-nc/4.0/

\section{REFERENCES}

1 Bowlus CL, Olson KA, Gershwin ME. Evaluation of indeterminate biliary strictures. Nat Rev Gastroenterol Hepatol 2016;13:28-37.

2 Scheuermann U, Widyaningsih R, Hoppe-Lotichius M, et al. Detection of benign hilar bile duct stenoses-a retrospective analysis in 250 patients with suspicion of Klatskin tumour. Ann Med Surg 2016;8:43-9.

3 Kalaitzakis E, Levy M, Kamisawa T, et al. Endoscopic retrograde cholangiography does not reliably distinguish
IgG4-associated cholangitis from primary sclerosing cholangitis or cholangiocarcinoma. Clin Gastroenterol Hepatol 2011;9:800-3.e2.

4 Navaneethan U, Njei B, Lourdusamy V, et al. Comparative effectiveness of biliary brush cytology and intraductal biopsy for detection of malignant biliary strictures: a systematic review and meta-analysis. Gastrointest Endosc 2015;81:168-76.

5 Sadeghi A, Mohamadnejad M, Islami F, et al. Diagnostic yield of EUS-guided FNA for malignant biliary stricture: a systematic review and meta-analysis. Gastrointest Endosc 2016;83:290-8.e1.

6 Heimbach JK, Sanchez W, Rosen CB, et al. Trans-peritoneal fine needle aspiration biopsy of hilar cholangiocarcinoma is associated with disease dissemination. HPB (Oxford) 2011;13:356-60.

7 El Chafic AH, Dewitt J, Leblanc JK, et al. Impact of preoperative endoscopic ultrasound-guided fine needle aspiration on postoperative recurrence and survival in cholangiocarcinoma patients. Endoscopy 2013;45:883-9.

8 Heinzow HS, Kammerer S, Rammes C, et al. Comparative analysis of ERCP, IDUS, EUS and CT in predicting malignant bile duct strictures. World J Gastroenterol 2014;20: 10495-503.

9 Chen YK, Parsi MA, Binmoeller KF, et al. Single-operator cholangioscopy in patients requiring evaluation of bile duct disease or therapy of biliary stones (with videos). Gastrointest Endosc 2011;74:805-14.

10 Kalaitzakis E, Webster GJ, Oppong KW, et al. Diagnostic and therapeutic utility of single-operator peroral cholangioscopy for indeterminate biliary lesions and bile duct stones. Eur J Gastroenterol Hepatol 2012;24:656-64.

11 Nanda A, Brown JM, Berger SH, et al. Triple modality testing by endoscopic retrograde cholangiopancreatography for the diagnosis of cholangiocarcinoma. Therap Adv Gastroenterol 2015;8:56-65.

12 Navaneethan U, Hasan MK, Kommaraju K, et al. Digital, single-operator cholangiopancreatoscopy in the diagnosis and management of pancreatobiliary disorders: a multicenter clinical experience (with video). Gastrointest Endosc 2016;84:649-55.

13 Yang JF, Sharaiha RZ, Francis G, et al. Diagnostic accuracy of directed cholangioscopic biopsies and confocal laser endomicroscopy in cytology-negative indeterminate bile duct stricture: a multicenter comparison trial. Minerva Gastroenterol Dietol 2016;62:227-33.

14 Caillol F, Bories E, Autret A, et al. Evaluation of pCLE in the bile duct: final results of EMID study: pCLE: impact in the management of bile duct strictures. Surg Endosc 2015;29: 2661-8.

15 van der Gaag NA, Rauws EAJ, van Eijck CHJ, et al. Preoperative biliary drainage for cancer of the head of the pancreas. N Engl J Med 2010;362:129-37.

16 Tol JA, van Hooft JE, Timmer R, et al. Metal or plastic stents for preoperative biliary drainage in resectable pancreatic cancer. Gut 2016;65:1981-7.

17 Sawas T, Al Halabi S, Parsi MA, et al. Self-expandable metal stents versus plastic stents for malignant biliary obstruction: a meta-analysis. Gastrointest Endosc 2015;82:256-67.e7.

18 Devière J, Reddy DN, Püspök A, et al. Successful management of benign biliary strictures with fully covered self-expanding metal stents. Gastroenterology 2014;147:385-95.

19 Khashab MA, Van der Merwe S, Kunda R, et al. Prospective international multicenter study on endoscopic 
ultrasound-guided biliary drainage for patients with malignant distal biliary obstruction after failed endoscopic retrograde cholangiopancreatography. Endosc Int open 2016;4:E487-96.
20 Alvarez-Sánchez M-V, Napoléon B. Review of endoscopic radiofrequency in biliopancreatic tumours with emphasis on clinical benefits, controversies and safety. World J Gastroenterol 2016;22:8257-70. 